\title{
CONHECIMENTO TRADICIONAL E USOS DO UMBUZEIRO (Spondias tuberosa Arruda) POR COMUNIDADES RURAIS DO SEMIÁRIDO, PARAÍBA, NORDESTE, BRASIL
}

\author{
TRADITIONAL KNOWLEDGE AND USES OF THE UMBUZEIRO (Spondias tuberosa \\ ARRUDA) BY RURAL SEMII-ARIID COMMUNITIES, PARAIIBA, NORTHEAST, BRAZIL
}

Rogério Paodjuenas ${ }^{1,2}$, Gabriela Maciel Costa ${ }^{2}$, Ernane Nogueira Nunes ${ }^{2}$, Flávia Oliveira Paulino ${ }^{1}$, Reinaldo Farias Paiva Lucena ${ }^{1,2^{*}}$

1- Pós-Graduação em Desenvolvimento e Meio Ambiente (PRODEMA). Centro de Ciências Exatas e da Natureza. Universidade Federal da Paraíba. Campus I. Cidade Universitária. Castelo Branco. CEP 58.033-455. João Pessoa, Paraíba, Brasil. 2- Laboratório de Etnobiologia e Ciências Ambientais. Departamento de Sistemática e Ecologia. Centro de Ciências Exatas e da Natureza. Universidade Federal da Paraíba. Campus I. Cidade Universitária. Castelo Branco. CEP 58.033-455. João Pessoa, Paraíba, Brasil. *Autor para correspondência: rlucena@ dse.ufpb.br

\section{RESUMO}

O umbuzeiro (Spondias tuberosa Arruda), pertencente à família Anacardiaceae, é uma das espécies nativas de maior importância para o semiárido brasileiro. O presente estudo registrou o conhecimento tradicional desta espécie por moradores de cinco comunidades rurais da Paraíba, Nordeste do Brasil. Foram estudadas as comunidades de São Francisco (Cabaceiras), Coelho (Remígio), Várzea Alegre (São Mamede), Capivara (Solânea) e Santa Rita (Congo), utilizando questionário semiestruturado. Foram entrevistados todos os chefes de família de todas as residências. Na comunidade São Francisco foram registradas 255 citações de uso, em Coelho 64 citações, em Várzea Alegre 68 citações, em Santa Rita 208 citações e em Capivara 339 citações, totalizando 934 citações. As categorias mais relevantes em todas as comunidades foram a alimentícia (146 citações em São Francisco, 38 em Coelho, 52 em Várzea Alegre, 154 em Capivara e 136 em Santa Rita) e forragem (65 citações em São Francisco, 13 em Coelho, 12 em Várzea Alegre, 91 em Capivara e 40 em Santa Rita). Em Várzea Alegre e Santa Rita a utilização do fruto in natura esteve presente em 59,62\% e 38,97\% das citações, respectivamente. Para a categoria forragem, registraram-se os usos das folhas e frutos, representando nas comunidades de Capivara (26,84\%), São Francisco (25,49\%) e Coelho (20,31\%). Nas comunidades São Francisco, Capivara e Santa Rita as mulheres conhecem mais sobre os usos da espécie do que os homens, sendo, respectivamente, $60,00 \%, 53,40 \%$ e $51,54 \%$. Já nas comunidades de Várzea e Coelho, os homens mostraram ter um conhecimento maior que as mulheres, sendo $51,47 \%$ e $51,56 \%$ respectivamente. As populações das comunidades demonstraram que $S$. tuberosa é de extrema importância para o seu dia-a-dia devido aos variados usos e categorias atribuídas à espécie. Palavras-chave: Caatinga, comunidades agrícolas, etnobotânica

\begin{abstract}
The umbu tree (Spondias tuberosa Arruda) belongs to the family Anacardiaceae and is one of the native species of greater importance for the Brazilian semiarid. The present study recorded the traditional knowledge of this species by residents of five rural communities of Paraíba, Northeast Brazil. The communities of São Francisco (Cabaceiras), Coelho (Remígio), Várzea Alegre (São Mamede), Capivara (Solânea) and Santa Rita (Congo) were studied using a semi-structured questionnaire. All household heads from all residences were interviewed. In the San Francisco community, 255 citations of used were recorded, in Coelho 64 citations, in Várzea Alegre 68 citations, in Santa Rita 208 citations, and in Capivara 339 citations, thus totaling 934 citations. The most relevant categories in all communities were food (146 citations in San Francisco, 38 citations in Coelho, 52 citations in Várzea Alegre, 154 citations in Capivara, and 136 citations in Santa Rita) and forage (65 citations in San Francisco, 13 quotations in Coelho, 12 quotations in Várzea Alegre, 91 quotations in Capivara, and 40 quotations in Santa Rita). In Várzea Alegre and Santa Rita the in natura use of the fruit was present in $59.62 \%$ and $38.97 \%$ of the citations, respectively. For the forage category, the uses of leaves and fruits were recorded, representing $26.84 \%$ in Capivara, 25.49\% in São Francisco, and 20.31\% in Coelho. Women from the communities of São Francisco, Capivara and Santa Rita knew more about the uses of the species than men, being $60.00 \%, 53.40 \%$ and $51.54 \%$, respectively. In the communities of Várzea Alegre and Coelho, men showed greater knowledge than women, being $51.47 \%$ and $51.56 \%$, respectively. Inhabitants of the surveyed communities have shown that $S$. tuberosa is of extreme importance for their daily life due to the varied uses and categories attributed to the species.
\end{abstract}

Keywords: Agricultural communities, Caatinga, ethnobotany 


\section{INTRODUÇÃO}

O umbuzeiro (Spondias tuberosa Arruda), também conhecido popularmente como imbuzeiro, taperebá, cajá-do-sertão, umbu e imbú, é uma das plantas que merece destaque dentre as espécies nativas do bioma Caatinga, embora também seja encontrada no Cerrado brasileiro. Esse destaque se dá por suas variadas possibilidades de utilização, mencionadas em diversos estudos científicos, que registraram usos que vão desde a alimentação humana e animal, até usos madeireiros e medicinais (LINS NETO et al., 2010; SOUZA e LORENZI, 2012; NASCIMENTO et al., 2013; NUNES et al., 2016).

Pertencente à família Anacardiaceae, o umbuzeiro é uma árvore de pequeno a médio porte, em torno de 2 a 10 metros de altura, atrofiado e retorcido de cor cinza, que projeta uma sombra densa e esparsa sobre o solo (SOUZA e LORENZI, 2012). Seu período de floração e frutificação na região Nordeste ocorre no período de estiagem (LINS NETO et al., 2010), onde mesmo nessa época conserva a copa frondosa (BERNARDES, 1999; MITCHELL e DALY, 2015). Suas folhas são compostas, alternas, pinadas, glabras quando adultas e folíolos ovalados. Suas flores são alvas, paniculadas, aromáticas e melíferas (SANTOS, 2015).

O umbuzeiro é uma planta frutífera, xerófita, caducifólia, perfeitamente adaptada às zonas mais secas do Nordeste do Brasil. Seu sistema radicular possui formato longo que se alastra horizontalmente próximo à superfície do solo, contudo muito desenvolvido podendo atingir profundidades superior a um metro, possuindo estruturas denominadas túberas ou xilopódios, conhecidas popularmente como batatas-do-umbu (MITCHELL e DALY, 2015). Essas estruturas são comestíveis, apresentando suculência pela quantidade de água armazenada e possuem um sabor adocicado (MITCHELL e DALY, 2015). Cada estrutura é capaz de armazenar em torno de $250 \mathrm{ml}$ de água (SILVA et al., 1991), podendo tanto essa reserva de água quanto a estrutura em si ser consumidas por humanos e animais em qualquer período, com apenas um único umbuzeiro podendo produzir cerca de duas toneladas de xilopódios (CAVALCANTI e RESENDE, 2006; BATISTA et al., 2015). Cabe ressaltar que são necessários estudos mais detalhados e específicos sobre os usos dos xilopódios, já que se dispõe de escassa literatura, embora apresentem enorme potencial devido à grande quantidade de carboidratos e água.

Seus frutos apresentam-se na forma de drupas, obovoides e subglobosas, possuindo polpa suculenta, quase aquosa quando madura, com sabor agridoce (MITCHELL e DALY, 2015). Tais características proporcionam a possibilidade do seu aproveitamento em diversas formas, como suco, doce, umbuzada (que é a mistura de leite com o suco da fruta e açúcar, sendo cozidos até formar uma pasta), cocada, entre outros (CAVALCANTI et al., 2000a;b; BASTOS et al., 2016). Seu endocarpo é muito resistente e nele está contida a semente propriamente dita (COSTA et al., 2015) que é rica em gordura e proteína, e o óleo extraído pode ser usado nas indústrias para fabricação de óleos e margarinas (MAIA, 2004).

O umbu é uma fruta tropical que apresenta uma produção expressiva na região Nordeste (SILVA-LUZ e PIRANI, 2015), sendo utilizada pelas populações desta região como uma das fontes econômicas e alimentares durante o período de frutificação (COSTA et al., 2015), que se inicia aproximadamente 25 dias após a floração e a maturação dos frutos (LIMA FILHO, 2008). Em época de safra, dezembro a março, variando a ocorrência de acordo com a região, há uma grande oferta de frutos de umbu, o que favorece uma exploração extrativista, principalmente voltada para o consumo in natura (SANTOS et al., 2008; TURINI, 2010; MOURA et al., 2013;) ou na industrialização para produção de diversos produtos alimentícios, como doces, sucos, geleias, entre outros (BORGES et al., 2011).

É considerada uma das espécies mais versáteis do semiárido brasileiro, da qual se utilizam as folhas, frutos, caule, galhos, raízes nos mais variados usos, como alimentício para humanos e animais, medicinal, construções, tecnológico, dentre outros, além de sua presença servir como abrigo contra o sol forte da região, ou simplesmente para dar sorte, espantar o mal olhado ou trazer boas energias; por isso, pode ser considerada uma árvore sagrada para o povo nordestino (BARRETO e CASTRO, 2010; LINS NETO et al., 2010).

Diante do exposto, o presente estudo buscou registrar e analisar o conhecimento que moradores de comunidades rurais do semiárido do estado da Paraíba, Nordeste do Brasil, possuem e que formas de utilização atribuem para o umbuzeiro (Spondias tuberosa Arruda). 


\section{MATERIAL E MÉTODOS}

\section{Contexto regional e local do trabalho}

O estudo foi realizado em cinco comunidades rurais da Paraíba, Nordeste do Brasil, em diferentes mesorregiões, sendo as comunidades de Capivara, no município de Solânea, Coelho, município de Remígio, ambas pertencentes à região do Curimataú. Nas comunidades de São Francisco, município de Cabaceiras/ e Santa Rita no Congo, ambas pertencentes à região do Cariri Velho, e a comunidade de Várzea Alegre, em São Mamede, pertencente à região do Seridó na Borborema (Figura $1)$.

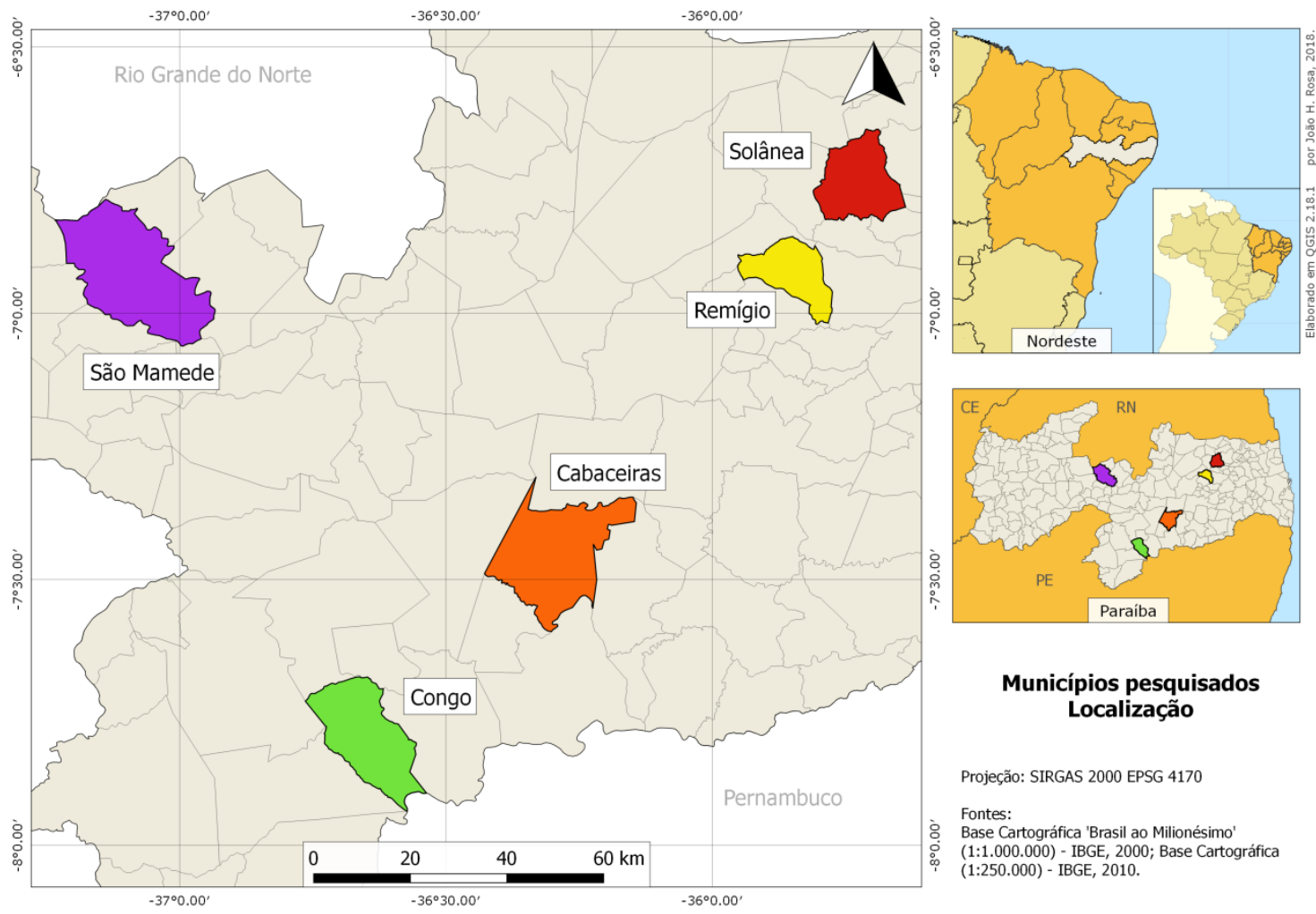

Figura 1 - Localização geográfica dos municípios e comunidades estudadas, sendo a comunidade de Capivara em Solânea, Coelho em Remígio, São Francisco em Cabaceiras, Santa Rita no Congo e Várzea Alegre em São Mamede, todas no Nordeste do Brasil.

\section{Solânea - Comunidade Capivara}

O município de Solânea localiza-se na mesorregião do Agreste e microrregião do Curimataú Oriental, entre as coordenadas $06^{\circ} 46^{\prime} 40^{\prime \prime} \mathrm{S}$ e $35^{\circ} 41^{\prime} 49^{\prime \prime} \mathrm{O}$, com altitude de 626 metros. Dista $138 \mathrm{~km}^{2}$ da capital do Estado, João Pessoa, com acesso pelas Rodovias BR 230, BR 041 e PB 105. Possui uma área territorial de 232,094 km², com densidade demográfica de 115,01 hab./km² (IBGE, 2010) e população de 26.689 habitantes (7.357 na zona rural e 19.332 na zona urbana). Faz divisa com os municípios de Casserengue, Dona Inês, Remígio, Arara, Barra de Santa Rosa, Borborema, Bananeiras e Cacimba de Dentro.

A comunidade Capivara dista aproximadamente $15 \mathrm{~km}$ do centro urbano, está subdividida em três localidades, Capivara I, II e III, possui economia baseada na agricultura familiar com destaque para o plantio de culturas de feijão e milho, além da criação de bovinos, caprinos e ovinos (RIBEIRO, 2013).

\section{Remígio - Comunidade Coelho}

O município de Remígio localiza-se na mesorregião do Agreste e Microrregião do Curimataú Oriental, entre as coordenadas geográficas $06^{\circ} 54^{\prime} 10^{\prime \prime} \mathrm{S}$ e $35^{\circ} 50^{\prime} 02^{\prime \prime} \mathrm{O}$, com altitude aproximada de 593 metros, e a uma distância aproximada de $157 \mathrm{~km}^{2}$ da capital do Estado, João Pessoa. Faz fronteiras com os municípios de Barra de Santa Rosa, Pocinhos, Esperança, Algodão de Jandaíra, Areia e Solânea. O acesso é feito a partir de João Pessoa, pelas Rodovias BR 230, BR 041 e PB 105. Apresenta uma população total de 17.581 habitantes (4.630 na zona rural e 12.951 na zona urbana) e uma área territorial de 178,064 km², com densidade demográfica de $98,73 \mathrm{hab} . / \mathrm{km}^{2}$ (IBGE, 2010). 
A comunidade Coelho está aproximadamente a uma distância de $7 \mathrm{~km}$ do centro urbano do município. A economia predominante também é a agricultura de subsistência, com destaque para a agricultura de sequeiro, tendo como principais produtos o milho e o feijão. Para a pecuária, tem destaque os rebanhos bovinos, sendo também criados caprinos e ovinos (COUTINHO, 2013).

\section{Cabaceiras - Comunidade São Francisco}

O município de Cabaceiras localiza-se na mesorregião da Borborema e microrregião do Cariri Oriental, delimitado pelas coordenadas $07^{\circ} 29^{\prime} 20^{\prime \prime} \mathrm{S}$ e $36^{\circ} 17^{\prime} 14^{\prime \prime} \mathrm{O}$. Possui uma área territorial de $452,920 \mathrm{~km}^{2}$, com população total de 5.035 habitantes (2.217 da zona urbana e 2.818 da zona rural) (IBGE, 2011). Apresenta temperatura média anual superior a $20^{\circ} \mathrm{C}$, sendo este um dos menores níveis pluviométricos do Brasil, menos de $300 \mathrm{~mm}$ de chuva durante todo o ano (IBGE, 2010). Limita-se com os municípios de Campina Grande, Santa Cruz do Capibaribe (Estado de Pernambuco), Boqueirão (ao leste) e São João do Cariri (ao oeste).

O presente estudo foi realizado na comunidade São Francisco que se subdivide em Caruatá de Dentro, Alto Fechado, Jerimum, Rio Direito e Malhada Comprida, distando aproximadamente $15 \mathrm{~km}$ da zona urbana. A economia da comunidade está voltada para as atividades agropastoris de subsistência, como destaque para criação de caprinos, ovinos e bovinos, e cultivos agrícolas de feijão, milho, palma, entre outros (LUCENA, 2013).

\section{Congo - Comunidade Santa Rita}

O município do Congo está localizado na mesorregião da Borborema e microrregião do Cariri Ocidental. Possui uma altitude aproximada de 480 metros, tem como coordenadas geográficas $7^{\circ} 47^{\prime} 41^{\prime}$ ' S e 36 39'42" O, distando aproximadamente $212 \mathrm{~km}$ da capital do Estado. Limita-se com os municípios de Serra Branca, Coxixola e Caraúbas; Camalaú e Sumé e ao sul com o Estado de Pernambuco. Apresenta uma população total de 4.692 habitantes (1.748 na zona rural e 2.944 na zona urbana) e uma área territorial de 333,469 km², com densidade demográfica de 14,06 hab./km² (IBGE, 2010).

A comunidade Santa Rita dista situa-se a aproximadamente oito quilômetros do centro urbano. $\mathrm{Na}$ economia tem por base principal a agricultura de subsistência, com destaque para cultura do milho e feijão. Já na pecuária tem destaque para criação de caprinos e ovinos, sendo também criados bovinos (COUTINHO, 2013).

\section{São Mamede - Comunidade Várzea Alegre}

O município de São Mamede está localizado na mesorregião do Sertão Paraibano e microrregião do Seridó Ocidental, no centro do Estado, entre as coordenadas 6 $6^{\circ} 55^{\prime} 37^{\prime \prime}$ S e $37^{\circ} 05^{\prime} 45^{\prime \prime}$ O. Possui 7.748 habitantes, sendo 3.837 homens e 3.911 mulheres, em uma área de $531 \mathrm{~km}^{2}$ (IBGE, 2010). O acesso pode ser feito a partir de João Pessoa pela Rodovia BR-230 no sentido Leste-Oeste com um percurso de aproximadamente 278 km. Limita-se com Ipueira (RN) e Várzea, com Várzea e Santa Luzia, Areia de Baraúnas, Passagem e Quixaba e Patos e São José de Espinharas, todas estas no Estado da Paraíba. O clima, segundo a classificação de Köppen, é do tipo Bsh (semiárido quente) com chuvas de verão, temperatura média anual de $28^{\circ} \mathrm{C}$ e os solos são pedregosos.

A economia da comunidade de Várzea Alegre é baseada na agropecuária, com a plantação de milho, feijão, algodão e mandioca, e criação de bovinos, caprinos e ovinos (LUCENA et al., 2012).

\section{Inventário etnobotânico}

A coleta dos dados etnobotânicos foi realizada com visitas a $100 \%$ das residências habitadas de cada comunidade. As informações foram obtidas por meio de formulários semiestruturados que continham perguntas sobre o conhecimento das pessoas e as formas de utilizações de S. tuberosa (ALBUQUERQUE e ANDRADE 2002a;b).

Foram entrevistados todos os chefes de família (homem e mulher) de cada residência (ALBUQUERQUE et al., 2010). Todos os entrevistados assinaram o Termo de Consentimento Livre e Esclarecido, que é solicitado pelo Conselho Nacional de Saúde por meio do Comitê de Ética em Pesquisa (Resolução 196/96). Este estudo também foi aprovado pelo Comitê de Ética em Pesquisa com Seres Humanos (CEP) do hospital Lauro Wanderley da Universidade Federal da Paraíba e registrado com protocolo CEP/HULW n ${ }^{\circ}$ 297/11. 
A espécie foi coletada, herborizada em campo, identificada e incorporada no Herbário Jaime Coelho de Moraes (EAN) da Universidade Federal da Paraíba, no Centro de Ciências Agrárias, com número de tombo 17556.

\section{Análise dos dados}

Os resultados foram elencados e organizadas em onze categorias utilitárias de acordo com a literatura etnobotânica especializada: alimentícia, combustível, construção, veterinário, forragem, tecnologia, veneno-abortiva, medicinal, sombra, mágico-religioso e ornamental (ALBUQUERQUE e ANDRADE 2002a;b; FERRAZ et al., 2006; LUCENA et al., 2007; LUCENA et al., 2012). Também foram incluídas subcategorias de uso, de acordo com as citações dos informantes, a fim de analisar com maior precisão e objetividade as informações registradas.

Os dados obtidos nas entrevistas foram plotados em planilhas e organizados em tabelas pelo Microsoft Excel $^{\circledR}$, em que foram analisadas as citações, separadas por gêneros (masculino e feminino) em cada comunidade. Os dados foram transformados em percentuais e tabelados para facilitar a interpretação por categoria, parte utilizada e formas de utilização, bem como suas finalidades. Também foram elencadas as principais formas de preparo alimentício e quais partes são utilizadas a fim de verificar o potencial desta categoria para a espécie.

\section{RESULTADOS}

\section{Conhecimento e utilização do umbuzeiro (Spondias tuberosa Arruda)}

Os moradores das comunidades rurais do semiárido brasileiro conhecem e fazem a utilização de diversas partes de $S$. tuberosa. De forma mais detalhada, na comunidade São Francisco foram registradas 255 citações de uso (102 homens e 153 mulheres), na comunidade Coelho com 64 citações de uso (33 homens e 31 mulheres). Em Várzea Alegre foram 68 citações ( 35 homens e 33 mulheres), Santa Rita com 208 (101 homens e 107 mulheres) e na comunidade Capivara com 339 (158 homens e 181 mulheres). Foram obtidas 934 citações de uso, sendo 505 feitas por mulheres e 429 por homem, organizadas em onze categorias.

As comparações das informações fornecidas por homens e mulheres evidenciam que as categorias mais relevantes foram as mesmas para as comunidades, sendo: alimentícia (146 citações), forragem (65 citações) e medicinal (20 citações) na cidade de Cabaceiras; Remígio com alimentícia (38 citações) e forragem (13 citações); São Mamede com alimentícia (52 citações) e forragem (12 citações); Solânea com alimentícia (154 citações), forragem (91 citações) e sombra (30 citações); no Congo se destacaram as categorias alimentícia (136 citações) e forragem (40 citações de uso).

Considerando o uso, podemos dizer que nas comunidades de Várzea Alegre e Santa Rita a categoria alimentícia obteve maior destaque, com 76,47\% e 65,38\%, respectivamente, assim como nas comunidades de Coelho (59,38\%), São Francisco $(57,25 \%)$ e Capivara $(45,43 \%)$. De forma mais detalhada, em Várzea Alegre a utilização do fruto in natura esteve presente em 59,62\% das citações, precedendo a umbuzada com $15,38 \%$, seguida pela fabricação do doce com $5,77 \%$ e do suco com $3,85 \%$. Em relação ao tubérculo (xilopódio), a utilização in natura deste tecido vegetal obteve $5,77 \%$ das citações, seguindo a produção do bolo com 3,85\%, doce, cocada e rapadura, apresentando 1,92\% cada.

Na comunidade de Santa Rita, a utilização do fruto in natura esteve presente em 38,97\% das citações, a umbuzada em $32,35 \%$, suco com $11,76 \%$, seguida pela fabricação do doce com $2,94 \%$ e picolé caseiro com $0,74 \%$. Em relação à utilização do tubérculo (xilopódio), a fabricação do doce apresentou 6,62\% das citações, a cocada com 3,68\% e a utilização in natura obteve 2,21\%.

$\mathrm{Na}$ categoria forragem, registraram-se apenas os usos das folhas e frutos, representando as comunidades de Capivara (26,84\%), São Francisco (25,49\%) e Coelho (20,31\%). No uso madeireiro, a categoria combustível foi registrada nos preparos de lenha e carvão, destacando-se Capivara $(7,67 \%)$, São Francisco (5,49\%) e Coelho (4,69\%), seguidos de Santa Rita (3,85\%) e Várzea Alegre (1,47\%).

$\mathrm{Na}$ categoria tecnologia, os informantes das comunidades de Coelho $(4,69 \%)$, Capivara $(0,59 \%)$ e São Francisco $(0,39 \%)$ disseram utilizar a espécie, para o preparo de artefatos como canga de carroça, cachimbo e barril.

Para categoria medicinal, foram registradas citações de uso nas comunidades de São Francisco $(7,84 \%)$, Santa Rita $(2,88 \%)$, Capivara $(2,65 \%)$ e Várzea Alegre $(1,47 \%$,$) . Os moradores utilizam a$ casca para dores em geral e efeito cicatrizante, a entrecasca para combater diarreia e dor na barriga, e o fruto e a folha para tratar enjoos durante a gravidez (Tabela1). 
Tabela 1 - Quantidade de citações totais na categoria medicinal e partes utilizadas na pesquisa realizada no semiárido da Paraíba, Nordeste do Brasil. Onde, $\mathrm{T}=$ Total, $\mathrm{H}=$ Homem, $\mathrm{M}=$ Mulher.

\begin{tabular}{lccccccc}
\hline \multirow{2}{*}{ Comunidade } & \multicolumn{3}{c}{ Citações } & \multicolumn{5}{c}{ Partes usadas $(\%)$} \\
\cline { 2 - 8 } & $\mathrm{T}$ & $\mathrm{H}$ & $\mathrm{M}$ & Entrecasca & Casca & Fruto & Folha \\
\hline Capivara & 9 & 4 & 5 & - & 11,11 & 77,78 & 11,11 \\
Coelho & - & - & - & - & - & - & - \\
São Francisco & 20 & 3 & 17 & - & 95 & - & 5 \\
Várzea Alegre & 1 & - & 1 & - & 100 & - & - \\
Santa Rita & 6 & 3 & 3 & 50 & 50 & - & - \\
\hline
\end{tabular}

Além de todos os usos registrados acima, $S$. tuberosa também foi citada nas comunidades Coelho $(7,81 \%)$ e Capivara $(6,78 \%)$ como bioindicador de fenômenos climáticos, principalmente como indicativo para períodos chuvosos (Tabela 2). Foram ainda citadas as categorias ornamental e sombra $(0,008 \%)$, veneno abortivo $(0,008 \%)$ e mágico-religioso $(0,01 \%)$.

Tabela 2 - Categorias de uso do umbu (Spondias tuberosa Arruda) citadas pelos moradores das comunidades rurais de Capivara, Coelho, Santa Rita, São Francisco e Várzea (Paraíba, Nordeste do Brasil).

\begin{tabular}{|c|c|c|c|c|}
\hline Comunidade & Categoria de uso & Parte utilizada & Forma de utilização & Finalidade \\
\hline \multirow{9}{*}{ Capivara } & Alimento & Fruto & $\begin{array}{l}\text { In natura } \\
\text { Doce, suco, umbuzada (mistura de } \\
\text { leite com a polpa da fruta e açúcar, } \\
\text { levando ao fogo para cozinhar), } \\
\text { dindin (típico gelado comestível } \\
\text { embalado em saquinhos) }\end{array}$ & \multirow[t]{3}{*}{ Alimentação } \\
\hline & & Tubérculo & In natura & \\
\hline & Forragem & $\begin{array}{l}\text { Folha } \\
\text { Tubérculo } \\
\text { Fruto }\end{array}$ & In natura & \\
\hline & \multirow[t]{2}{*}{ Medicinal } & Folha & Coloca de molho e bebe a água & Enjoo na gravidez \\
\hline & & Casca & Lambedor & Tosse \\
\hline & Ornamental & Completo & \multirow{2}{*}{ Plantada nos quintais } & Ornamentação \\
\hline & Sombra & Completo & & Sombreamento \\
\hline & Tecnologia & Madeira & Cachimbo, barril & Utilização diversa \\
\hline & Combustível & Madeira & Lenha, carvão & $\begin{array}{l}\text { Preparação dos } \\
\text { alimentos (Fogão a } \\
\text { lenha) }\end{array}$ \\
\hline \multirow{7}{*}{ Coelho } & Alimento & Fruto & In natura, suco, umbuzada, doce & \multirow{2}{*}{ Alimentação } \\
\hline & Forragem & $\begin{array}{l}\text { Fruto } \\
\text { Folha }\end{array}$ & In natura & \\
\hline & Mágico religioso & Completo & Plantada nos quintais & Mal olhado \\
\hline & Medicinal & Madeira & Lambedor & Tosse e gripe \\
\hline & Ornamental & Completo & Plantada nos quintais & Ornamentação \\
\hline & Combustível & Madeira & Lenha & $\begin{array}{l}\text { Preparação dos } \\
\text { alimentos (Fogão a } \\
\text { lenha) }\end{array}$ \\
\hline & Tecnologia & Madeira & Cachimbo & Utilização diversa \\
\hline \multirow{6}{*}{ São Francisco } & Alimento & $\begin{array}{l}\text { Fruto } \\
\text { Tubérculo }\end{array}$ & $\begin{array}{l}\text { Doce, umbuzada, in natura, suco, } \\
\text { dindin } \\
\text { In natura, cocada, doce }\end{array}$ & Alimentação \\
\hline & Combustível & Madeira & Carvão, lenha & $\begin{array}{l}\text { Preparação dos } \\
\text { alimentos (Fogão a } \\
\text { lenha) }\end{array}$ \\
\hline & Construção & Madeira & Tábua & $\begin{array}{l}\text { Aplicação diversas } \\
\text { em construção }\end{array}$ \\
\hline & Veterinário & Casca & Infusão na água & Limpa o parto \\
\hline & Forragem & $\begin{array}{l}\text { Folha } \\
\text { Fruto }\end{array}$ & In natura & Alimentação \\
\hline & Tecnologia & Madeira & Carroça & $\begin{array}{l}\text { Canga e acessórios } \\
\text { para carroça }\end{array}$ \\
\hline
\end{tabular}




\begin{tabular}{|c|c|c|c|c|}
\hline & Veneno abortivo & Folha & In natura & $\begin{array}{lr}\text { Animais } & \text { comendo } \\
\text { na mata } & \text { podem } \\
\text { abortar } & \\
\end{array}$ \\
\hline São Francisco & Medicinal & Casca & Lambedor, decocção & $\begin{array}{l}\text { Tosse } \\
\text { Cicatrizante } \\
\text { Calmante }\end{array}$ \\
\hline & & Folha & Molho, decocção & $\begin{array}{l}\text { Calmante } \\
\text { Inflamação em geral }\end{array}$ \\
\hline & Sombra & Completo & Plantada nos quintais & Sombreamento \\
\hline & Alimento & $\begin{array}{l}\text { Fruto } \\
\text { Tubérculo }\end{array}$ & $\begin{array}{l}\text { In natura, doce, suco, umbuzada, } \\
\text { picolé, sorvete } \\
\text { In natura, cocada, doce }\end{array}$ & Alimentação \\
\hline & Forragem & $\begin{array}{l}\text { Folha } \\
\text { Fruto }\end{array}$ & In natura & Alimentação \\
\hline & Mágico religioso & Completo & Plantada nos quintais & Mal olhado \\
\hline Sonto Pito & Ornamental & Completo & Plantada nos quintais & Ornamentação \\
\hline Santa Rita & Sombra & Completo & Plantada nos quintais & Sombreamento \\
\hline & Combustível & Madeira & Carvão, lenha & $\begin{array}{l}\text { Preparação dos } \\
\text { alimentos (fogão a } \\
\text { lenha) }\end{array}$ \\
\hline & Medicinal & Entrecasca & Mascar & Diarreia \\
\hline & Tecnologia & Madeira & Construção de pilão & $\begin{array}{l}\text { Pilar grãos para } \\
\text { alimentação }\end{array}$ \\
\hline & & Fruto & In natura, doce, umbuzada, suco & \\
\hline & Alimento & Tubérculo & Bolo, cocada, rapadura, doce & Alimentacão \\
\hline & Forragem & $\begin{array}{l}\text { Folha } \\
\text { Fruto }\end{array}$ & In natura & \\
\hline Várzea Alegre & Medicinal & Casca & $\begin{array}{l}\text { Coloca de molho a casca e bebe a } \\
\text { água }\end{array}$ & Diarreia \\
\hline & Ornamental & Completo & Plantada nos quintais & Ornamentação \\
\hline & Sombra & Completo & Plantada nos quintais & Ornamentação \\
\hline & Combustível & Madeira & Lenha & $\begin{array}{l}\text { Preparação dos } \\
\text { alimentos (fogão a } \\
\text { lenha) }\end{array}$ \\
\hline
\end{tabular}

\section{Preparo e utilização do fruto}

Em todos os municípios foram registrados usos de $S$. tuberosa no preparo de alimentos caseiros, com registro de 13 tipos de comidas, sendo 6 em Cabaceiras, 4 em Remígio, 7 em São Mamede, 7 em Solânea e 7 em Congo. As mais citadas foram umbuzada, doce, suco e utilização in natura do fruto (Tabela 3). As partes mais citadas para o preparo dos alimentos foram o fruto e o tubérculo (Figura 2).

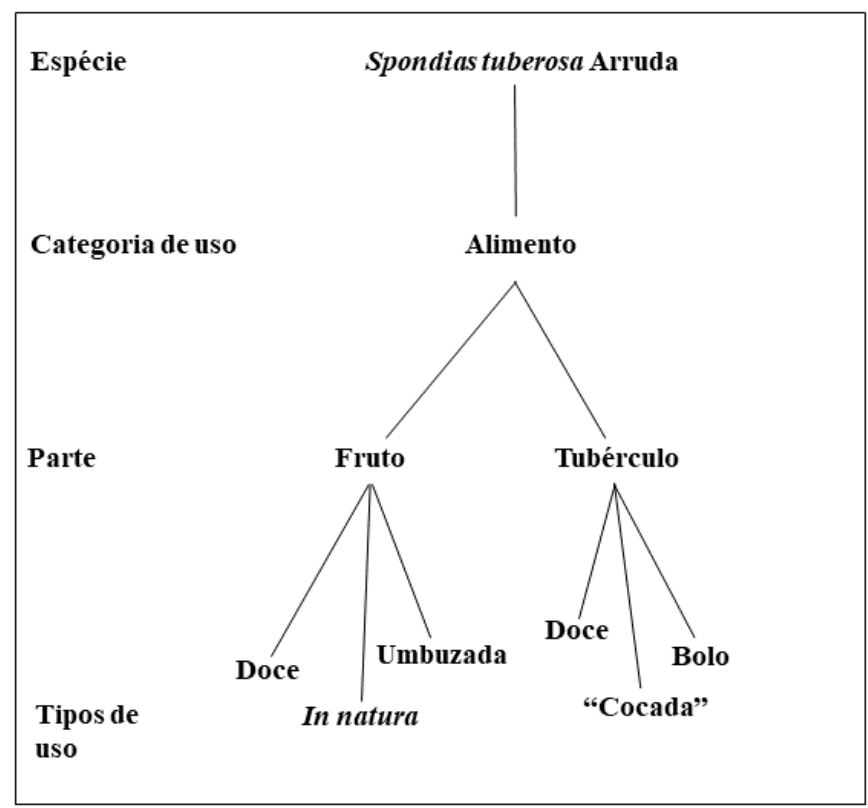

Figura 2 - Partes que mais se destacaram na categoria alimento, de acordo com moradores das comunidades rurais de Capivara, Coelho, São Francisco, Santa Rita e Várzea Alegre Cariri. Paraíba, Nordeste, Brasil. 
Para o preparo como alimento, foram relatadas várias formas, dentre elas: 1) cozido, que consiste em colocar o fruto na água juntamente com o açúcar e deixar cozinhar por um determinado tempo; 2) triturado, onde o fruto é passado no liquidificador; 3) ralado, onde o xilopódio é colocado para secar e depois ralado, para se transformar em farinha; e 4) molho, que consiste em colocar frutos, folhas ou cascas dentro d'água por um determinado tempo e depois consumir a água.

As formas de preparo mais citadas foram umbuzada, doce, mousse, cocada e geleia, com 26 citações em Capivara, 8 em Coelho, 47 em São Francisco, 62 citações em Santa Rita e 13 citações em Várzea Alegre.

\section{Geração do conhecimento sobre Spondias tuberosa Arruda}

Nas comunidades São Francisco, Capivara e Santa Rita, as mulheres conhecem mais sobre os usos atribuídos à $S$. tuberosa em relação aos homens, sendo respectivamente $60 \%, 53,40 \%$ e $51,44 \%$. Já nas comunidades de Várzea e Coelho os homens mostraram ter um conhecimento maior que as mulheres: $51,47 \%$ e $51,56 \%$, respectivamente.

Tabela 3 - Alimentos e citações de usos do umbu nas comunidades rurais de Várzea Alegre, Santa Rita, São Francisco, Coelho e Capivara. Paraíba, Nordeste do Brasil.

\begin{tabular}{lccccc}
\hline $\begin{array}{l}\text { Forma de } \\
\text { preparo }\end{array}$ & Capivara & Coelho & S. Francisco & Santa Rita & Várzea Alegre \\
\hline Doce & 2 & 3 & 9 & 13 & 4 \\
Umbuzada & 22 & 5 & 86 & 44 & 8 \\
In natura & 93 & - & - & 56 & 34 \\
Picolé & - & 4 & - & 1 & - \\
Suco & 34 & - & - & - & - \\
Mousse & 1 & - & - & - & - \\
Vitamina & 1 & - & 1 & - & - \\
Geleia & 1 & - & - & 1 & - \\
Dindin & - & - & 2 & 5 & 1 \\
Sorvete & - & - & - & - & 2 \\
Cocada & - & - & - & - & 1 \\
Bolo & - & - & & & - \\
Rapadura & - & - & - & & \\
\hline
\end{tabular}

Das categorias de uso, as mulheres mostram-se mais conhecedoras dos alimentos com 59,59\% em São Francisco, 52,63\% em Coelho e 62,34\% em Santa Rita; na categoria combustível, 57,14\% em São Francisco, 100\% Várzea Alegre e 75\% em Santa Rita; na categoria forragem, 53,38\% em São Francisco, 53,85\% em Coelho, 51,65\% em Capivara e 52,50\% em Santa Rita; na categoria medicinal, 85,00\% em São Francisco, 100\% em Várzea Alegre, 55,56\% em Capivara e 50\% em Santa Rita; na categoria ornamental, $100 \%$ das citações em Várzea Alegre; na categoria sombra, $60 \%$ em São Francisco e $100 \%$ em Várzea Alegre; na categoria tecnologia, 100\% em São Francisco e 66,67\% em Coelho; na categoria construção, 100\% em São Francisco; na categoria mágico-religioso, 100\% em Coelho; na categoria bioindicador, 56,52\% na comunidade Capivara; e na categoria veterinária, $50 \%$ na comunidade de Santa Rita.

Ao contrário, os homens conhecem mais sobre a categoria alimentícia com 53,85\% em Várzea Alegre; na categoria combustível 100\% em Coelho; e 53,85\% em Capivara; na categoria forragem com 58,33\% na comunidade de Várzea Alegre; na categoria medicinal, 50\% em Santa Rita; na categoria ornamental, $100 \%$ em Coelho; 66,67\% em Capivara e 100\% em Santa Rita; na categoria sombra, 76,67\% em Capivara e 64,29\% em Santa Rita; na categoria tecnologia, com 100\% em Capivara e Santa Rita; na categoria construção, $100 \%$ em Capivara; na categoria veneno-abortivo, 100\% em São Francisco; na categoria veterinária, $100 \%$ em São Francisco e 50\% na comunidade de Santa Rita; e na categoria bioindicador, $80 \%$ em Coelho (Tabela 4).

A maioria dos informantes relatou ter adquirido o conhecimento de forma vertical, sendo, na maior parte, por meio dos avós e pais, seguindo dos agricultores e vizinhos devido à convivência. Já em relação à transmissão de conhecimento registramos que está sendo passado dos pais para os filhos, e também de forma circular para os vizinhos e outros que procurarem informações. 
Tabela 4 - Categorias de uso e número de citações por homens $(\mathrm{H})$ e por mulheres $(\mathrm{M})$ nas comunidades de Capivara, Coelho, São Francisco, Santa Rita e Várzea Alegre (Paraíba, Nordeste, Brasil).

\begin{tabular}{lcccccccccc}
\hline \multirow{2}{*}{ Categoria } & \multicolumn{2}{c}{ Capivara } & \multicolumn{2}{c}{ Coelho } & \multicolumn{2}{c}{ São Francisco } & \multicolumn{2}{c}{ Santa Rita } & \multicolumn{2}{c}{ Várzea Alegre } \\
\cline { 2 - 10 } & H & M & H & M & H & M & H & M & H & M \\
\hline Alimento & 58 & 96 & 18 & 20 & 59 & 87 & 65 & 71 & 28 \\
Combustível & 14 & 12 & 3 & - & 6 & 8 & 2 & 6 & - \\
Construção & 1 & - & - & - & - & 1 & - & - & - & - \\
Forragem & 44 & 47 & 6 & 7 & 29 & 36 & 19 & 21 & 7 & 5 \\
Medicinal & 4 & 5 & - & - & 3 & 17 & 3 & 3 & - & 1 \\
Tecnologia & 2 & - & 1 & 2 & - & 1 & 1 & - & - & - \\
Outros & 35 & 21 & 5 & 1 & 2 & 3 & 10 & 5 & - & 2 \\
Veterinário & & & - & - & 1 & - & 1 & 1 & - & - \\
Veneno- abortivo & - & - & - & - & 2 & - & - & - & - & - \\
Mágico- religioso & - & - & - & 1 & - & - & - & - & - \\
\hline Total & 158 & 181 & 33 & 31 & 102 & 153 & 101 & 107 & 35 \\
\hline
\end{tabular}

\section{DISCUSSÃO}

\section{Conhecimento e utilização do umbuzeiro}

De modo geral, o conhecimento sobre $S$. tuberosa está distribuído entre os membros das comunidades estudadas. Essa uniformização no conhecimento pode estar agregada ao fato de que os moradores utilizam a espécie para fins alimentícios, tanto para humanos como para animais, como apontam estudos recentes (NUNES et al., 2015; MERTENS et al., 2017), onde praticamente todos os moradores citam algum uso da espécie para esta categoria, mesmo que seja o fruto in natura.

A literatura tem registrado a importância e o uso do umbuzeiro na alimentação humana na região do semiárido brasileiro, sendo essa espécie uma das principais fontes potenciais de subsistência e renda para algumas comunidades rurais dessa região, como visto em vários estudos (ALBUQUERQUE e ANDRADE, 2002; ALBUQUERQUE et al., 2005; ARÉVALO-MARÍN et al., 2015), o que definitivamente faz todos os autores especializados na área concordarem sobre a versatilidade e importância dessa espécie para a região semiárida do Nordeste brasileiro.

Estudos também foram realizados sobre $S$. tuberosa e evidenciaram, além da importância cultural, forte potencial econômico, principalmente para o potencial agroindustrial dos frutos, devido ao sabor e aromas peculiares, e do xilopódio (SILVA et al., 1987; MENDES 1990; CAVALCANTI et al., 2000). Por outro lado, há muitos registros na literatura de trabalhos focados em outras espécies, pertencentes ao gênero Spondias, em destaque também Spondias sp. e S. mombin L. (LIMA et al., 2002; LIRA-JÚNIOR et al., 2005; SOARES et al., 2006; MERTENS et al., 2017). Isso enfatiza a necessidade de mais pesquisas com foco em $S$. tuberosa em virtude de sua grande importância cultural e econômica, já mencionadas nas citações deste trabalho.

A comercialização dos frutos do umbuzeiro nas comunidades de São Francisco, Capivara, Coelho, Várzea Alegre e Santa Rita é pouco desenvolvida, embora dados da literatura já indiquem a importância socioeconômica da comercialização para as comunidades tradicionais da região há quase 20 anos (CAVALCANTI et al., 2000b; COSTA et al., 2001), e talvez por falta de interesse político, como o planejamento de ações públicas, a situação continue a mesma.

\section{Preparo e utilização do fruto}

O umbu costuma ser consumido nas comunidades rurais do semiárido nordestino, principalmente in natura e na forma de suco, mas sua polpa é muito usada em doces, sorvetes, licores e na tradicional "umbuzada" (NUNES et al., 2018). Nas comunidades de Coelho, São Francisco, Capivara, Várzea Alegre e Santa Rita o quadro não foi diferente.

Os moradores utilizavam o fruto para suco, mousse, vitamina, picolé e cocada, além dos usos já citados. Para Lins Neto (2008), no semiárido, o uso madeireiro da espécie é uma prática em abandono, muito embora os moradores das comunidades façam uso como carvão e lenha, como registrado no estudo de Arévalo-Marín et al. (2015), e também registrado neste trabalho, mas não recebendo destaque como algumas outras categorias.

A utilização do umbuzeiro como indicador de fenômenos climáticos também foi registrada, assim como em outros estudos na região do Cariri Paraibano (ABRANTES et al., 2011), e tem sua experiência reforçada pela fala dos informantes: "Quando a planta flora muito é sinal de chuva." (I.V., 25 anos); "Pé florado é sinal de inverno bom!" (M.N., 53 anos). 
O uso medicinal também foi abordado em pequena escala pelos moradores, utilizando-se a casca e as folhas como preparar lambedor, para usos como calmante e inflamação em geral. O que pode ser observado na literatura é que os compostos encontrados nas cutículas de ambas às faces foliares do umbuzeiro levam à proteção e maior resistência a algumas doenças, atividade antisséptica, anestésica, anti-inflamatória, antioxidante (TAIZ e ZEIGER, 2004, SIQUEIRA et al., 2016; SAMEH et al., 2018).

Outro fator a ser levado em consideração pelo uso medicinal em pequena escala pode ser a curta distância das comunidades rurais para as áreas urbanas, onde é mais fácil adquirir os fármacos sintéticos, ou a própria ação das políticas públicas que em alguns casos desacreditam na medicina popular, distribuem gratuitamente fármacos ou comercializam a preços reduzidos, subsidiados pelo Governo, fatores que precisam ser investigados com maiores critérios (estatísticos, culturais etc.), pois podem estar interferindo na vitalidade do conhecimento tradicional.

Vale ressaltar também que a utilização medicinal das folhas de $S$. tuberosa merecem maiores investigações para identificação dos compostos encontrados, já que o presente estudo apresenta o resultado de uso geral, com foco no conhecimento tradicional empírico e não de substâncias específicas para tal finalidade.

\section{Geração e transmissão do conhecimento}

O conhecimento das mulheres mostrou-se superior em relações ao dos homens entre as comunidades estudadas. Entretanto, o maior número de citações entre as mulheres foi para as finalidades medicinais e alimentícias, onde geralmente as mulheres são as responsáveis pela residência e o cuidado dos filhos e os homens se relacionam mais ao uso e manejo do umbuzeiro em atividades diversas (VIU et al., 2010).

Esse conhecimento dos homens se dá, principalmente, porque a atuação deles está voltada para a alimentação e cuidado dos animais, ou seja, para os trabalhos no campo (NUNES et al., 2015, ARÉVALO-MARÍN et al., 2015; NUNES et al., 2016,). Figueiredo et al. (1993) já evidenciavam que as mulheres possuíam um conhecimento distinto dos homens, principalmente em relação ao uso de plantas medicinais e alimentícias (VIU et al., 2010).

O uso veneno-abortivo, mesmo sendo pouco citado, merece ser relatado de forma detalhada, pois através das observações, quando os animais estão no período de gestação, os moradores evitam ao máximo possível aproximá-los de $S$. tuberosa, pois os animais pastando podem forragear as folhas e isso pode acarretar no aborto da gestação. Não foi encontrado nada na literatura que confirmasse que substâncias são responsáveis por tal fato ou se realmente as folhas são responsáveis por isso.

No contexto geral, percebe-se que a manutenção do conhecimento sobre o umbuzeiro é muito importante para os moradores das zonas rurais do semiárido brasileiro, tanto para os homens quanto para as mulheres, cada um explorando a sua forma, evidenciando, de fato, a versatilidade da espécie, que tantos estudos relatam e que existem muitos conhecimentos a serem explorados, difundidos entre os moradores e as famílias. A transmissão do conhecimento tradicional é repassada entre gerações, entre vizinhos, mostrando a importância que os recursos naturais possuem no cotidiano de populações rurais, tanto por homens quanto por mulheres (SILVA DO Ó et al., 2016; OLER et al., 2017), mas que se o poder público investisse na capacitação, os cientistas divulgassem os resultados de seus trabalhos para as comunidades e todos se unissem no propósito de trabalhar o potencial desta espécie, poderíamos ter soluções econômicas e de caráter ambiental, que facilitassem o uso e manejo adequado para esta região que tanto sofre com os períodos de seca.

\section{CONSIDERAÇÕES FINAIS}

As populações das comunidades rurais de Capivara, Coelho, Santa Rita, São Francisco e Várzea Alegre demonstraram que o umbuzeiro é de grande importância para o seu dia-a-dia, devido aos variados usos e categorias atribuídas à espécie, com destaque para a categoria alimentícia, principalmente por apresentar diversas formas de preparo e partes vegetais utilizadas. O conhecimento entre homens e mulheres foi de forma geral semelhante, sendo mantido e transmitido às novas gerações, o que possibilita sua perpetuação.

Sugerimos a realização de estudos específicos na área de gastronomia a fim de introduzir essa importante espécie nos cardápios de restaurantes, hotéis, dentre outros, devido as suas possibilidades de preparo e sabor típico e único, o que pode contribuir para uma melhoria socioeconômica das comunidades rurais do semiárido brasileiro. 


\section{AGRADECIMENTOS}

Os autores agradecem aos moradores das comunidades estudadas que se propuseram a participar e ajudar na pesquisa. Agradecemos a Universidade Federal da Paraíba - UFPB, por todo suporte logístico nas atividades de campo.

O presente trabalho foi realizado com apoio da Coordenação de Aperfeiçoamento de Pessoal de Nível Superior - Brasil (CAPES) - Código de Financiamento 001.

\section{REFERÊNCIAS}

ABRANTES, P. M.; SOUSA, R. F.; LUCENA, C. M.; LUCENA, R. F. P.; PEREIRA, D. D. Aviso de chuva e de seca na memória do povo: O caso do Cariri Paraibano. Revista de Biologia e Farmácia, Campina Grande, v. 5, n. 2. p. 18-24, 2011.

ALBUQUERQUE, U. P.; ANDRADE, L. H. C. Uso de recursos vegetais da caatinga: o caso do agreste do Estado de Pernambuco (Nordeste do Brasil). Interciência, v.27, p. 336-345, 2002.

ALBUQUERQUE, U. P.; ANDRADE, L. H. C. Conhecimento botânico tradicional e conservação em uma área de caatinga no estado de Pernambuco, Nordeste do Brasil. Acta Botânica Brasílica, v. 16, p. 273-285, 2002 b.

ALBUQUERQUE, U. P.; ANDRADE, L. H. C. Uso de recursos vegetais da Caatinga: o caso do agreste do Estado de Pernambuco (Nordeste do Brasil). Interciência, v. 27, p. 336-345, 2002a.

ALBUQUERQUE, U. P.; ANDRADE, L. H. C.; SILVA, A. C. O. Use of plant resources in a seasonal dry forest (Northeastern Brazil). Acta Botanica Brasilica, v. 19, n.1, p. 27-38, 2005.

ALBUQUERQUE, U. P.; LUCENA, R. F. P.; ALENCAR, N. L. Métodos e técnicas para coleta de dados etnobiológicos. in: ALBUQUERQUE, U.P.; LUCENA, R.F.P.; CUNHA, L.V.F.C. (eds.), Métodos e técnicas na pesquisa etnobiológica e etnoecológica. Núcleo publicações em ecologia e etnobotânica aplicada (NUPEEA), Recife, Brasil, p. 39-64, 2010, 559 p.

ARÉVALO-MARÍN, E.; FARIAS LIMA, J. R.; PALMA, A. R. T.; LUCENA, R. F. P.; DA CRUZ, D. D. Traditional Knowledge in a Rural Community in the Semi-Arid Region of Brazil: Age and gender patterns and their implications for plant conservation. Ethnobotany Research and Applications, v. 14, p. 331-344, 2015.

BARRETO, L. S.; CASTRO, M. S. Boas práticas de manejo para o extrativismo sustentável do umbu. Florianópolis: Embrapa - Recursos Genéticos e Biotecnologia, 2010. 35 p.

BASTOS, J. S.; MARTINEZ, E. A.; SOUZA, S. M. A. Características físico-químicas da polpa de umbu (Spondias tuberosa Arruda Camara) comercial: Efeito da concentração. Journal of Bioenergy and Food Science, v. 3, n. 1, p. 11-16, 2016.

BATISTA, F. R. C. SILVA, S. M.; SANTANA, M. F. S.; CAVALCANTE, A. R. O umbuzeiro e o Semiárido brasileiro. Campina Grande, PB, Editora: INSA - Instituto do Semiárido Brasileiro, 2015, 72 p.

BERNARDES, N. As caatingas. Estudos Avançados, São Paulo, vol. 13, n. 35, p.69-78, 1999.

BORGES, S. V.; MARTINS, M. L. A.; MESQUITA, K. S.; FERRUA, F. Q.; CAVALCANTI, N. D. B. Efeito de aditivos sobre a cor durante o armazenamento de doces de umbu (Spondias tuberosa Arr. Câmera) verde e maduro. Alimentos e Nutrição. v. 22, n. 2, p. 307-313, 2011.

CAVALCANTI, N. B.; LIMA, J. B.; RESENDE, G. M.; BRITO, L. T. L. Ciclo reprodutivo do umbuzeiro (Spondias tuberosa Arruda) no semiárido do Nordeste, Revista Ceres, v. 47, n. 272, p.421-439 2000 a.

CAVALCANTI, N. B.; RESENDE, G. M.; BRITO, L. T. L. (2000b) Processamento do fruto do imbuzeiro (Spondias tuberosa Arr. Cam.). Ciência. Agrotecnologia. Lavras, v. 24, n. 1, p.252-259.

CAVALCANTI, N. B.; RESENDE, G. M. Ocorrência de xilopódio em plantas nativas de imbuzeiro. Revista Caatinga, v.19, n.3, p.287-293, 2006.

COSTA, F. R. B.; SILVA, M. M. A.; ARAÚJO, V. S. Uso sustentável do umbuzeiro: estratégia de convivência com o semiárido. Campina Grande: INSA, 15p.: il. 2015.

COSTA, N. P.; BRUNO, R. L. A.; SOUZA, F. X.; LIMA, E. D. P. A. Efeito do estádio de maturação do fruto e do tempo de pré-embebição de endocarpos na germinação de sementes de umbuzeiro (Spondias tuberosa Arruda). Revista Brasileira de Fruticultura, Jaboticabal - SP. v. 23, n. 3, p. 738-741, 2001.

COUTINHO, P. C. Importância relativa de plantas medicinais no semiárido da Paraíba (Nordeste do Brasil). Trabalho de conclusão de curso (Licenciatura em Ciências Biológicas). Centro de Ciências Agrárias, 2013.

FERRAZ, J. S. F.; ALBUQUERQUE, U. P.; MEUNIER, I. M. J. Valor de uso e estrutura da vegetação lenhosa às margens do Riacho do Navio, Floresta, PE, Brasil. Acta Botanica Brasilica. v.20, n. 1, p. 125-134, 2006.

FIGUEIREDO, G. M.; LEITÃO-FILHO, H. F.; BEGOSSI, A. Ethnobotany of atlantic forest coats communities: diverity of plants use in Gamboa (Itacuruçá Island, Brazil). Human Ecology. v. 21. p. 419-430, 1993.

GALEANO, G. Florest use at the Pacific Coast Chocó, Colombia: a quantitative Approach. Economic Botany. v. 54, n. 3, p. 358-376, 2000. 
INSTITUTO BRASILEIRO DE GEOGRAFIA E ESTATÍSTICA (IBGE). Censo Brasileiro de 2010. Rio de Janeiro: IBGE, 2012.

LIMA FILHO, J. M. P. Ecofisiologia do umbuzeiro. In: Spondias no Brasil: umbu, cajá e espécies afins. Recife: IPA. p. 31-39, 2008.

LIMA, E. D. P.; LIMA, C. A. A.; ALDRIGUE, M. L.; GONDIM, P. J. S. Caracterização física e química dos frutos da umbu-cajazeira (Spondias spp) em cinco estádios de maturação, da polpa congelada e néctar. Revista Brasileira de Fruticultura, Jaboticabal - SP, v. 24, n. 2, p. 338-343, 2002.

LINS NETO, E. M. F.; PERONI, N.; ALBUQUERQUE, U. P. Traditional knowledge and management of Umbu (Spondias tuberosa, Anacardiaceae): an endemic species from the semi-arid region of Northeastern Brazil. Economic Botany, v. 64, n. 1, p. 11-21, 2010.

LUCENA, C. M.; COSTA, G. G. S.; CARVAlHO, T. K. N.; GUERRA, N. M.; QUIRINO, Z. G. M.; LUCENA, R. F. P. Uso e conhecimento de cactáceas no município de São Mamede (Paraíba, Nordeste do Brasil). Biofar, Volume especial, p. 121-133, 2012.

LUCENA, C. M. Uso e diversidade de Cactáceas em uma comunidade rural do Cariri Oriental da Paraíba (Nordeste do Brasil). Trabalho de conclusão de Curso (Bacharel em Ciências Biológicas) Centro de Ciências Agrárias. Universidade Federal da Paraíba, 2013.

LUCENA, C. M.; COSTA, G. G. S.; CARVAlHO, T. K. N.; GUERRA, N. M.; QUIRINO, Z. G. M.; LUCENA, R. F. P. Uso e conhecimento de cactáceas no município de São Mamede (Paraíba, Nordeste do Brasil). Biofar, Volume especial, p. 121-133, 2012.

LUCENA, R. F. P.; ALBUQUERQUE, U. P.; ALMEIDA, C. F. C. B. R.; FLORENTINO, A. T. N.; FERRAZ, J. S. F. Plantas úteis da região semiárida do Nordeste do Brasil - Um olhar sobre a sua conservação e uso sustentável. Environ monit assess. v. 125, p. 281-290, 2007.

LUCENA, R. F. P.; ALBUQUERQUE, U. P.; ALMEIDA, C. F. C. B. R.; FLORENTINO, A. T. N.; FERRAZ, J. S. F. Plantas úteis da região semiárida do Nordeste do Brasil - Um olhar sobre a sua conservação e uso sustentável. Environ monit assess. v. 125, p. 281-290, 2007.

MAIA, G. N. Caatinga: árvores e arbustos. Leitura \& Arte Ed. São Paulo, p. 354-363, 2004.

MERTENS, J.; GERMER, J.; SIQUEIRA FILHO, J. A.; SAUERBORN, J. Spondias tuberosa Arruda (Anacardiaceae), a threatened tree of the Brazilian Caatinga?. Brazilian Journal of Biology, v. 77, n. 3, p. 542$552,2017$.

MITCHELL, J. D.; DALY, D. C. A revision of Spondias L. (Anacardiaceae) in the Neotropics. PhytoKeys, n. 55, p. $1,2015$.

MOURA, F. T.; SILVA, S. M.; SCUNEMANN, A. P. P.; MARTINS. Umbu tree fruit stored under modified and ambient atmospheric conditions at different maturity stages. Revista Ciência Agronômica, v. 44, n. 4, p. 764$772,2013$.

NASCIMENTO, V. T.; LUCENA, R. F. P.; MACIEL, M. I. S.; ALBUQUERQUE, U. P. Knowledge and use of wild food plants in areas of dry seasonal forests in Brazil. Ecology of food and nutrition, v. 52, n. 4, p. 317$343,2013$.

NUNES, A. T.; CABRAL, D. L. V., AMORIM, E. L. C., DOS SANTOS, M. V. F., ALBUQUERQUE, U. P. Plants used to feed ruminants in semi-arid Brazil: A study of nutritional composition guided by local ecological knowledge. Journal of Arid Environments, v. 135, p. 96-103, 2016.

NUNES, A. T.; LUCENA, R. F. P.; SANTOS, M. V. F.; ALBUQUERQUE, U. P. Local knowledge about fodder plants in the semi-arid region of Northeastern Brazil. Journal of Ethnobiology and Ethnomedicine, v. 11, n. 1 , p. $12,2015$.

NUNES, E. N.; GUERRA, N. M.; ARÉVALO-MARÍN, E; ALVES, C. A. B.; NASCIMENTO, V. T.; CRUZ, D. D.; LADIO, A. H.; SILVA, S. M.; OLIVEIRA, R. S.; LUCENA, R. F. P. Local botanical knowledge of native food plants in the semiarid region of Brazil. Journal of Ethnobiology and Ethnomedicine, v. 14, n. 49, p. 1-13, 2018

OLER, J. R. L.; AMOROZO, M. C. M. Ethnobotany and on farm conservation of cassava (Manihot esculenta Crantz) in small scale agriculture in the State of Mato Grosso, Brazil. Interações (Campo Grande), v. 18, n. 4, p. 137-153, 2017.

RIBEIRO, J. E. S. A Hipótese da aparência ecológica e importância de plantas úteis: Testando diferentes valores de uso. (Trabalho de conclusão de curso, Ciências Agrárias). Bananeiras, Universidade Federal da Paraíba, 2013.

SAMEH, S.; AL-SAYED, E.; LABIB, R. M.; SINGAB, A. N. A Phytochemical and Pharmacological Review. Evidence-Based Complementary and Alternative Medicine, v. 2018, 2018.

SANTOS, C. A. F.; RODRIGUES, M. A.; ZUCCHI, M. I. Variabilidade genética do umbuzeiro no SemiÁrido brasileiro, por meio de marcadores AFLP. Pesquisa Agropecuária Brasileira. v. 43, n. 8, p. 1037-1043, 2008.

SANTOS, M. M. O. Aspectos morfoanatômicos e fisiológicos de plantas jovens de amburana (Amburana cearensis (Fr. All. A. C. Smith) e umbuzeiro (Spondias tuberosa Arr. Com.). 90 f. Tese (Doutorado Acadêmico em Recursos Genéticos Vegetais)- Universidade Estadual de Feira de Santana, Feira de Santana, 2015. 
SILVA, A. Q.; SILVA, H.; SILVA, H, M. M.; CARDOSO, E. A. Estado nutricional de plantas de umbu (Spondias tuberosa Arr. Cam.) e absorção de NPK pelos frutos por ocasião da colheita. Revista Brasileira de Fruticultura. Cruz das Almas, v. 13, n. 4. p. 259-263, 1991.

SILVA DO Ó, K. D.; SILVA, G. H.; LEITE, I. A. Estudo etnobotânico de plantas medicinais em duas comunidades no Estado da Paraíba, Brasil. Biodiversidade, v. 15, n. 2, 2016.

SILVA-LUZ, C. L.; PIRANI, J. R. 2015. Anacardiaceae in: Lista de Espécies da Flora do Brasil para 2020. Jardim Botânico do Rio de Janeiro. Disponivel em: <http://floradobrasil.jbrj.gov.br/jabot/floradobrasil/FB4405>.

SIQUEIRA, S.; MICHELL, E.; FÉLIX-SILVA, J.; ARAÚJO, L. M. L.; FERNANDES, J. M.; CABRAL, B.; FREITAS FERNANDES-PEDROSA M. Spondias tuberosa (Anacardiaceae) leaves: profiling phenolic compounds by HPLC-DAD and LC-MS/MS and in vivo anti-inflammatory activity. Biomedical Chromatography, v. 30, n. 10, p. 1656-1665, 2016.

SOUSA, R. F. A aparência ecológica pode explicar a utilização de espécies úteis em uma comunidade rural na região do Paraibano? (Monografia em Licenciatura - Ciências Biológicas) - Departamento de Biologia. Universidade Federal da Paraíba, 2011.

SOUZA, V. C.; LORENZI, H. Botânica Sistemática. $3^{\text {a }}$ edição, Instituto Plantarum. Nova Odessa, 2012.

TAIZ, L.; ZEIGER, E. Fisiologia vegetal. Ed. Artmed, Porto Alegre. p. 309-334, 2004.

TURINI, E. Umbu (fruto). Companhia Nacional de Abastecimento. Disponível em:<http://www.conab.gov.br/OlalaCMS/uploads/arquivos/11_06_30_17_46_37_umbujunho..pdf>. Acesso em: 8 ago de 2017.

VIU, A. F. M.; OLIVEIRA, M. A.; OLIVEIRA CAMPOS, L. Z. Etnobotânica: uma questão de gênero?. Revista Brasileira de Agroecologia, v. 5, n. 1, 2010. 